\title{
Epidemiological and clinical characteristics of acute gastroenteritis according to their etiology (rotavirus or other) in children younger than 5 years old treated in a private institution in the City of Buenos Aires
}

\author{
Cristian García Roig, M.D., ${ }^{a}$ Natalia Larre, M.D., ${ }^{b}$ Horacio Pastene, Biochemist, ${ }^{c}$ \\ Laura Gutiérrez, B.S., Juan Vaccaro, Biochemist, ${ }^{b}$ Juan Antonio Sciarrotta' M.D., ${ }^{a, b}$ \\ Alejandro Lepetic, M.D ${ }^{d}$., Camilo Moreno, M.D. ${ }^{d}$ and Alejandro Ellis, M.D. ${ }^{b}$
}

\begin{abstract}
Introduction. Acute gastroenteritis is a common disease in children. Rotavirus is the major etiologic agent.

Objectives. To describe the epidemiological and clinical characteristics of acute gastroenteritis according to their etiology (rotavirus or other) in children younger than 5 years old in a private institution in the City of Buenos Aires. Secondary objective: to analyze related costs.

Material and Methods. Cross sectional, descriptive, observational study conducted during one year in children younger than 5 years old with gastroenteritis. The presence of rotavirus was diagnosed with the VIKIA ${ }^{\circledR}$ Rota-Adeno test. Demographic, clinical and immunization data were collected. A univariate data analysis was performed.

Results. A total of 275 patients were included; $18.5 \%$ of them were $\mathrm{R}+$. Rotavirus was more common in children younger than 2 years old and in the period between March and June. The cases of rotavirus gastroenteritis were more severe, required more hospitalizations (OR 2.07; $95 \%$ CI 1.17-7.13), and resulted in higher costs. In the sample studied, the immunization outcome measure reduced the risk of rotavirus infection. Conclusions. Acute gastroenteritis caused by rotavirus were different from other etiologies in that they had a seasonal peak and in relation to the median age of patients, the severity of the condition, the association with hospitalization and the increase in costs.

Key words: rotavirus, gastroenteritis, rotavirus vaccine, children.
\end{abstract}

http:/ /dx.doi.org/10.5546/aap.2013.218

\section{INTRODUCTION}

Financed by

GlaxoSmithKline.

E-mail address:

Dr. García Roig:

garciaroig@gmail.com

Conflict of interest:

See page 222

Received: 1-8-2012

Accepted: 9-25-2012

common pediatric diseases and the third cause of mortality among children younger than 5 years old worldwide. ${ }^{1,2}$ Rotavirus is the most common cause of acute diarrhea, with more than 125 million cases and over 611000 deaths occurring every year in children younger than
5 years old. ${ }^{2}$ In Latin America and the Caribbean, rotavirus causes $25 \%$ ( 2 millions) of all diarrhea related medical consultations, $40 \%$ of children with diarrhea require hospitalization (190 000), and there are 5000 deaths every year. ${ }^{3,4}$ It is estimated that rotavirus is accountable for $39 \%$ of consultations due to gastroenteritis (130 000) and $42 \%$ of hospitalizations (20 000) $)^{5-7}$ in Argentina, with a direct annual cost that would be equivalent to 27.7 million dollars. ${ }^{6}$ Mortality and morbidity associated with diarrhea are determined by the population's socioeconomic and cultural level, and their closeness to health care centers. ${ }^{7}$

There are significant regional differences in relation to the access to the healthcare system. ${ }^{5}$ Data provided by the Ministry of Health of the Argentine Republic indicated that the mortality rate from diarrhea in the provinces of the North is three times higher than the national mean rate. ${ }^{7}$

The main objective of this study was to describe the epidemiological and clinical characteristics of acute gastroenteritis according to their etiology (rotavirus or other) in children younger than 5 years old in a private medical facility of the City of Buenos Aires. The secondary objective of the study was to identify household costs related to acute gastroenteritis.

\section{MATERIAL AND METHODS \\ Design}

Cross sectional, descriptive, observational study conducted between November $9^{\text {th }}, 2009$ and November $8^{\text {th }}$, 
2010 in outpatients with gastroenteritis (treated at the Emergency Departmen and consulting offices) or patients hospitalized because of gastroenteritis in the Sanatorio Mater Dei de Buenos Aires. All patients had a private health insurance. A longitudinal follow-up was also done for all patients. Seven days after their enrollment in the study, patients' parents were contacted by phone as many times as necessary to complete a survey (see electronic Annex) on patients' evolution.

\section{Eligibility criteria}

Inclusion criteria

- Children younger than 60 months old.

- Consultation due to acute gastroenteritis.

- Informed consent signed by parents or legal guardian in the first 48 hours after consultation or hospitalization.

- Stool sample for rotavirus screening within 5 days of clinical presentation.

\section{Exclusion criteria}

- Persistent diarrhea (more than 14 days from the onset of symptoms).

- Antibiotics administered within 48 hours before.

- Hospital discharge in the past 48 hours.

- Presence of known gastrointestinal disease or condition that may cause diarrhea.

- Hospital acquired diarrhea occurring 48 hours after hospitalization for other clinical condition.

\section{Definitions}

Acute gastroenteritis: episode of diarrhea lasting less than 14 days.

Diarrhea: three or more bowel movements, more loose than normal, in 24 hours.

Fever: axillary temperature $\geq 37.5^{\circ} \mathrm{C}$, ear or rectal temperature $\geq 38^{\circ} \mathrm{C}$.

\section{Hospitalization}

The diagnostic and management guidelines of the Argentine Society of Pediatrics for acute diarrhea in children were used. ${ }^{8}$ The Vesikari scale (Table 1) allows to discriminate between mild (up to 6 points), moderate (7-10 points) and severe (more than 10 points) cases. ${ }^{9}$

\section{Human resources for patient hospitalization}

Fifteen health care providers were in charge of admitting patients. All of them had received specific training on how to fill in the record form and the informed consent.

\section{Stool rotavirus screening}

The stool sample was sent to the lab for a quick qualitative rotavirus screening test (VIKIA ${ }^{\circledR}$ Rota-Adeno Bio Mèrieux) that uses immunochromatography technology with specific monoclonal antibodies.

\section{Costs}

Direct medical costs included costs at the outpatient office, Emergency Department and hospitalization, telephone follow-up, complementary exams and medications. Once approved and signed by parents, a witness and the doctor, the patient would be included. Relatives or legal guardians were given a copy.

TABLE 1. Diarrhea severity scale (modified by Ruuska and Vesikari)

\begin{tabular}{|c|c|}
\hline Signs and symptoms & Points \\
\hline \multicolumn{2}{|c|}{ Duration of diarrhea (in days) } \\
\hline $1-4$ & 1 \\
\hline 5 & 2 \\
\hline$\geq 6$ & 3 \\
\hline \multicolumn{2}{|c|}{ Maximum number of bowel movements/24 h } \\
\hline $1-3$ & 1 \\
\hline $4-5$ & 2 \\
\hline$\geq 6$ & 3 \\
\hline \multicolumn{2}{|c|}{ Duration of vomiting (in days) } \\
\hline 1 & 1 \\
\hline 2 & 2 \\
\hline$\geq 3$ & 3 \\
\hline \multicolumn{2}{|c|}{ Maximum number of vomits $/ 24 \mathrm{~h}$} \\
\hline 0 & 0 \\
\hline 1 & 1 \\
\hline $2-4$ & 2 \\
\hline$\geq 5$ & 3 \\
\hline \multicolumn{2}{|l|}{ Fever } \\
\hline$\leq 37.0^{\circ} \mathrm{C}$ & 0 \\
\hline $37.1-38.4^{\circ} \mathrm{C}$ & 1 \\
\hline $38.5-38.9^{\circ} \mathrm{C}$ & 2 \\
\hline$\geq 39^{\circ} \mathrm{C}$ & 3 \\
\hline \multicolumn{2}{|l|}{ Dehydration } \\
\hline None & 0 \\
\hline $1-5 \%$ & 2 \\
\hline$\geq 6 \%$ & 3 \\
\hline \multicolumn{2}{|l|}{ Treatment } \\
\hline None & 0 \\
\hline Rehydration & 1 \\
\hline Hospitalization & 2 \\
\hline Total score & 20 \\
\hline
\end{tabular}




\section{Immunization schedule}

Patients were considered vaccinated if they had received at least one dose of Rotarix ${ }^{\circledR}$ (GlaxoSmith-Kline Biologicals, Rixensart, Belgium) rotavirus human vaccine or RotaTeq ${ }^{\circledR}$ (Merck, Whitehouse Station, NJ, USA) human-bovine vaccine, according to their age; and they were considered to have completed their immunization schedule if they had received two or three doses, depending on the manufacturing pharmaceutical company.

\section{Ethical considerations}

The study was conducted in accordance with the Good Clinical Practice (GCP) guidelines, the Declaration of Helsinki (October 1996), and the laws in force in Argentina (as established by the Drug, Food and Technology Administration of Argentina [ANMAT]). The study was approved by the Bioethics Committee of the Sanatorio Mater Dei.

The informed consent form was provided to the parents or legal guardians of the children who met the inclusion criteria. Median duration of diarrhea, duration of vomiting, axillary temperature, and duration of hospitalization were not significant when comparing $\mathrm{R}+$ and $\mathrm{R}$ patients (Table 2).

\section{Statistical analysis}

For data analysis, the STATA 9.1 software was used. For the description of cases studied, mean, standard deviation, median and minimum and maximum values were used as continuous outcome measures; relative and absolute frequencies were used as categorical outcome measures. To evaluate the association between categorical outcome measures the chi squared test was used. To compare continuous outcome measures as per rotavirus status (positive, negative) and immunization (yes, no), the Wilcoxon rank-sum test was used, because they did not meet alleged normal values. The significance level was established at $5 \%$.

\section{RESULTS}

For study inclusion, 291 patients were considered, and a stool sample was otained from 275 of them (Figure 1). Out of these patients, $74.9 \%$ had received the vaccine. The number of $\mathrm{R}+$ cases by month is shown in Figure 2. Four cases had bloody diarrhea.

Non medical direct costs included transportation, the use of additional diapers and hiring additional staff for looking after the patients. Overheads included loss of working hours and perfect attendance bonuses.

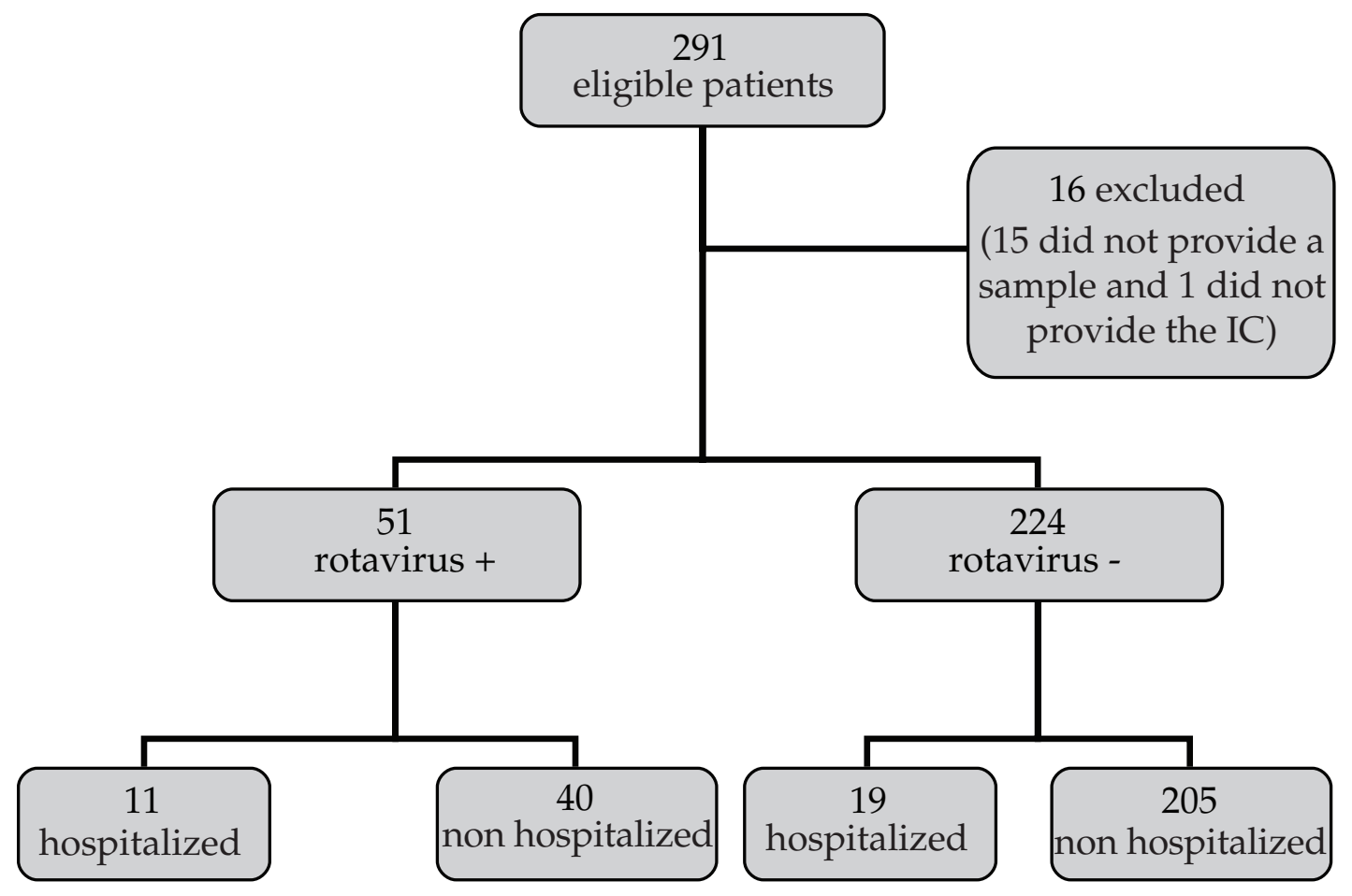


Median score in the Vesikari scale, the maximum number of vomits per day and dehydration were significant in $\mathrm{R}+$ patients (Table 2).

The risk of being $\mathrm{R}+$ was significantly higher among non vaccinated patients.

There were $34 / 206 R+$ vaccinated children versus $16 / 59$ non vaccinated children $(p<0.05)$.

Out of 30 hospitalized children, 22 had mild to moderate dehydration and 8 were referred by their primary care pediatrician due to oral intolerance. Eleven patients were $\mathrm{R}+$. The association between hospitalization and $\mathrm{R}+$ had an OR of $2.97(1.17-7.13) p=0.0068$. Out of these $11 \mathrm{R}+$ patients, only 2 were vaccinated.

The telephone survey was administered to the 275 patients included, with a median follow-up of 35 days.
The median number of visits to a health care center in $R+$ patients was 2 versus 1 in $\mathrm{R}$ - patients $(p=0.0353)$. The median number of calls to the pediatrician was 3 in $\mathrm{R}+$ children versus 2 in $\mathrm{R}$ - patients $(p=0.0008)$. Loss of working hours was higher in $\mathrm{R}+$ cases $(p=0.0010)$ in the 160 cases that reported lost hours.

No differences were found in transportation expenses $(p=0.3435)$, loss of perfect attendance bonuses ( $p=0.2533$ ), or additional staff hired.

There were no deaths because of diarrhea in our study.

\section{DISCUSSION}

In this study, we observed a smaller proportion of rotavirus gastroenteritis when compared to

FIGURE 2. Number of samples positive for rotavirus per month

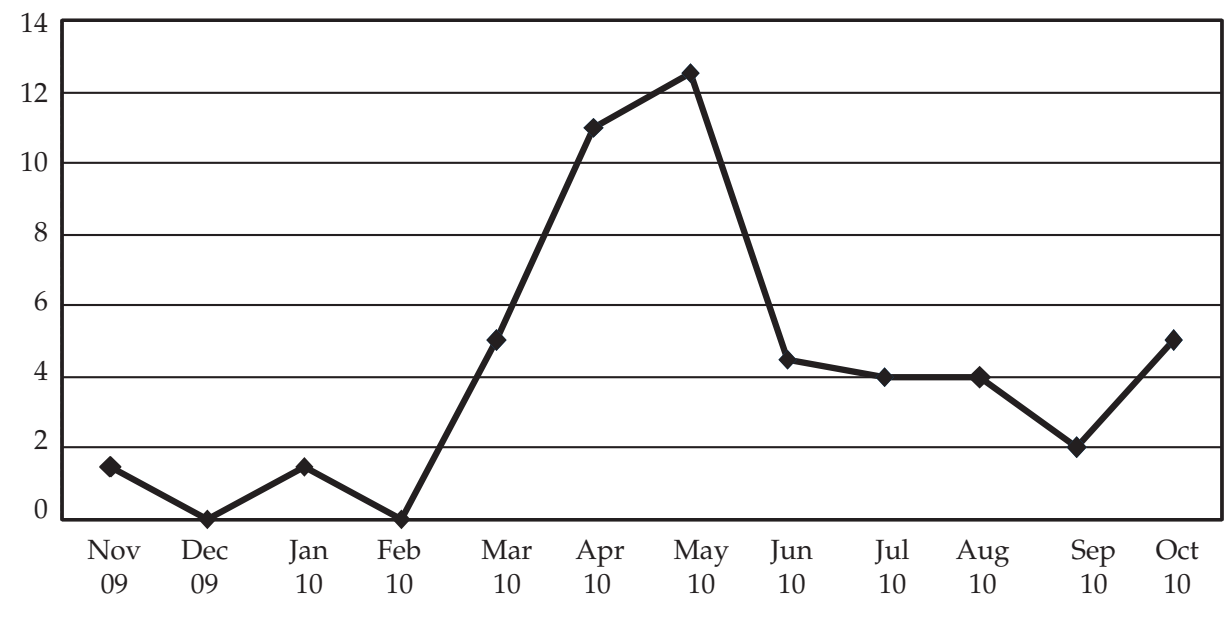

TABLE 2. Clinical data of patients enrolled by presence of rotavirus in stools

\begin{tabular}{|c|c|c|c|}
\hline & Rotavirus + & Rotavirus - & p \\
\hline Duration of diarrhea (in days) & 2.55 (SD 1.8) & 2.7 (SD 1.7) & NS \\
\hline $\begin{array}{l}\text { Maximum number of bowel } \\
\text { movements per day }\end{array}$ & 4.1 (SD 2.8) & 4.7 (SD 2.7) & NS \\
\hline Duration of vomiting (in days) & $2.5(\mathrm{SD} 1.8)$ & $2.1(\mathrm{SD} 1.5)$ & NS \\
\hline Axillary temperature (in ${ }^{\circ} \mathrm{C}$ ) & 36.7 (SD 0.7) & $36.6(\mathrm{SD} 0.8)$ & NS \\
\hline Dehydration & $9 / 15$ & $13 / 224$ & $\mathrm{p}=0.005$ \\
\hline $\begin{array}{l}\text { Maximum number of vomits } \\
\text { (in } 24 \text { hours) }\end{array}$ & 4.3 (SD 3.1) & 3.1 (SD 2.7) & $\mathrm{p}=0.001$ \\
\hline Vesikari scale & $6.4(\mathrm{SD} 2.8)$ & $5.1(\mathrm{SD} 2.1)$ & $\mathrm{p}=0.003$ \\
\hline $\begin{array}{l}\text { Duration of hospitalization } \\
\text { (in days) }\end{array}$ & $3.64(\mathrm{SD} 0.81)$ & 3.33 (SD 1.88) & NS \\
\hline
\end{tabular}


other studies conducted in Argentina, ${ }^{5}$ and to data obtained at our institution in previous years.

The proportion of $\mathrm{R}+$ results between 2005 and 2009 was $30.88 \%, 26.77 \%, 17.64 \%, 13.96 \%$, and $15.42 \%$, respectively (unpublished data). It should be noted that a human vaccine for rotavirus has been marketed in Argentina since 2006. The human-bovine resortant rotavirus vaccine was later incorporated.

In a study based on consultations and hospitalizations in public hospitals that included children younger than 36 months old, overall rotavirus detection was 32\% (Argentina 39\%, Chile $34 \%$, and Venezuela $29 \%) .{ }^{10}$ In the multicenter study conducted in Argentina in $2006,38.4 \%$ of the cases of diarrhea was caused by rotavirus. ${ }^{5}$

The median age in our study was the same as in the above mentioned multicenter study. ${ }^{5}$ Most cases occurred between 6 and 24 months old, and took place in the months corresponding to autumn and winter in the southern hemisphere, consistent with the bibliography.

Most patients did not require hospitalization, which is also consistent with the data provided by the Hospital de Niños "Dr. Ricardo Gutiérrez". However, there was a marked difference with other health care centers in the North of Argentina, ${ }^{5}$ probably in relation to access to the health care system (transportation, prehospital services).

$\mathrm{R}+$ patients did not have a higher number of daily bowel movements nor protracted diarrhea than R- patients, consistent with the bibliography. ${ }^{11}$ Only one retrospective study found an increase in $\mathrm{R}+{ }^{12}$ In our study, it was found that $\mathrm{R}+$ children had a higher number of vomiting per day. This coincides with studies conducted in Latin America ${ }^{5}$ and Europe. ${ }^{13}$ No differences were seen in relation to the duration of vomiting between $\mathrm{R}+$ and R-patients, as in a study from Germany, ${ }^{10}$ and no differences were observed regarding the presence of fever at the time of admission nor its duration, as seen in other studies. ${ }^{5,11}$ There were two studies that found higher temperatures in $\mathrm{R}+$ children. ${ }^{12,13} \mathrm{R}+$ diarrhea increased the risk of dehydration, which is consistent with multicenter Argentine ${ }^{5}$ and European ${ }^{11}$ studies. Severity as per the Vesikari scale was worse in $\mathrm{R}+$ patients, as seen in other publications. ${ }^{13,14}$

The rate of patients that required hospitalization was higher than the number indicated by the Hospital de Niños "Dr. Ricardo
Gutiérrez" and the findings of the SPRIK study, ${ }^{15}$ but it was similar to the number reported by the REVEAL study. ${ }^{11}$

The proportion of $\mathrm{R}+$ children out of the total number of hospitalized patients was similar to the proportion found in the Argentine multicenter study $(42 \%)^{5}$ and the German study $(45 \%) .{ }^{12}$ However, it was lower than in the publications from Chile $(49 \%),{ }^{10}$ the SPRIK study $(56 \%)^{14}$ and the REVEAL study $(60 \%),{ }^{11}$ but higher than the rate found in Brazil (15.6\%). ${ }^{16,17}$ Results from other studies from Europe and Israel were diverse. 13,18,19

If a comparison is made between studies from Europe and the United States, the paradigm repeats itself: mortality from rotavirus gastroenteritis is low, but it causes a high expense in health resources and has a high impact on employment. ${ }^{20}$ It is estimated that, in the United States, 2.7 million children have diarrhea between 6 months old and 5 years old. Before the introduction of the vaccine, this used to generate a 264 million dollar expense for the health system and 1 billion dollars for the community. ${ }^{21}$

In our study, $\mathrm{R}+$ children had more visits to health care providers and their parents or legal guardians had to call their pediatrician more times, therefore they lost more hours of work.

In the sample studied, the immunization outcome measure was associated with a lower risk of rotavirus gastroenteritis and, as a consequence, of dehydration and hospitalization.

The coverage documented in our study was similar to the coverage achieved with $\geq 1$ dose of the vaccine in children younger than 5 months old in the United States as of June 2009 (72\%), obtained in eight sentinel sites after the first vaccine was approved..$^{22}$

\section{CONCLUSIONS}

Acute gastroenteritis caused by rotavirus was more common during autumn and winter, and in children younger than 2 years old. When compared to other etiologies, it was more severe and had a higher risk of hospitalization, leading to an increase in costs.

\section{Conflict of interest}

- Cristian García Roig, M.D., received fees from GlaxoSmithKline as Principal Investigator.

- Natalia Larre, M.D., received fees as grant holder for her field work.

- Juan Vaccaro, M.D., received fees from GlaxoSmithKline as a member of the lab of the Sanatorio Mater Dei for doing the 
rotavirus and adenovirus screening tests in the stool samples of 275 patients enrolled in the protocol.

- Alejandro Lepetic, M.D., is the Medical Director of South America of GlaxoSmithKline Biologicals, Argentina.

- Camilo Moreno, M.D., is an epidemiologist working at GlaxoSmithKline Biologicals, Latin America.

- Alejandro Ellis, M.D., is an independent lecturer for GlaxoSmithKline Argentina (Vaccines) and Novartis (Vaccines).

\section{Acknowledgments}

To the doctors on duty, working at the Emergency Department who duly admitted patients to the study.

To Verónica Gibson, M.D., for translating the abstract and making a critical review of the article.

\section{Annex}

Telephone survey of patients included in the study (electronic format).

\section{REFERENCES}

1. WHO. The Global Burden of Disease: 2004 update. World Health Organization, Geneva, Switzerland: WHO, 2008.

2. Parishes UD, Burton A, Lanata C, Boschi-Pinto C, et al. Global mortality associated with rotavirus disease in children in 2004. J Infect Dis 2009;200(Suppl 1):S9-S15.

3. Centers for Disease Control and Prevention (CDC). Rotavirus surveillance worldwide 2001-2008. MMWR Morb Mortal Wkly Rep 2008;57(46):1255-7.

4. DeOliveira LH, Danovaro-Holliday MC, Matus CR, Andrus $\mathrm{JK}$. Rotavirus vaccine introduction in the Americas: progress and lessons learned. Expert Rev Vaccines 2008;7:345-53.

5. Gentile A, Sabbaj L, Uboldi A, Caruso M, et al. Impacto de la gastroenteritis por rotavirus en la Argentina. Rev Hosp Niños B Aires 2008;50:226:1-8.

6. Gómez J, Nates S, Castagnaro N, Espul C y cols. En anticipación de una vacuna antirrotavirus: revisión de estudios epidemiológicos sobre la diarrhea por rotavirus en la Argentina. Rev Panam Salud Pública/Pan Am J Public Health 1998;3(6):375-84.

7. Gómez J, Sordo ME, Gentile A. Epidemiologic patterns of diarrheal disease in Argentina: estimation of rotavirus burden disease. Pediatr Infect Dis J 2002;21(9):843-50.

8. Sociedad Argentina de Pediatría. Consenso Nacional. Diarrea aguda en la infancia. Actualización sobre criterios de diagnóstico y tratamiento; 2003. [Accesed on: September 25, 2012].Available at: http://www.sap.org.ar/docs/ profesionales/consensos/diarreagu.pdf.

9. Ruuska T, Vesikari T. Rotavirus disease in Finnish children: use of numerical scores for clinical severity of diarrhoeal episodes. Scand J Infect Dis 1990;22(3):259-67.

10. O'Ryan M, Pérez-Schael I, Mamani N, Peña A, et al. Rotavirus-associated medical visits and hospitalizations in South America: a prospective study at three large sentinel hospitals. Pediatr Infect Dis J 2001;20(7):685-93.

11. Giaquinto C, van Damme P, Huet F, Gothefors L, et al. Clinical consequences of Rotavirus acute gastroenteritis in Europe, 2004-2005: The REVEAL Study. J Infect Dis 2007;195(Suppl 1):S26-35.

12. Wiegering V, Kaiser J, Tappe D, Weissbrich, et al. Gastroenteritis in childhood: a restrospective study of 650 hospitalized pediatric patients. Int J Infect Dis 2011;15(6):e-401-e7.

13. Forster J, Guarino A, Parez N, Imoraga F, et al. Hospital based surveillance to estimate the burden of rotavirus gastroenteritis among european children younger than 5 years of age. Pediatrics 2009;123(3):e393-e400.

14. Gladstone BP, Ramani S, Mukhopadhya I, Muliyil J, et al. Protective effect of natural rotavirus infection in an indian birth cohort. N Engl J Med 2011;365(4):337-46.

15. Diez Domingo J, Baldo JM, Patrzalek M, Pazdiora P, et al. Primary Care Broad surveillance to estimate the burden of rotavirus gastroenteritis among children aged less than 5 years in six European countries. Eur J Pediatr 2011;170(2):213-22.

16. Carneiro NB, Diniz-Santos DR, Fagundes SQ, Neves LL, etal. Clinical and Epidemiological Aspects of Children Hospitalizedwith Severe Rotavirus-Associated Gastroenteritis in Salvador, BA, Brazil. Brazn I Infect Dis 2005;9(6):525-28.

17. Sartori AM, Valentim J, de Soárez PC, Novaes HM. Rotavirus morbidity and mortality in children in Brazil. Rev Panam Salud Pública 2008;23(2):92-100.

18. Lanzieri TM, Costa I, Shafi FM, Cunha MH, et al. Trends in hospitalization from all-cause gastroenteritis in children younger than 5 years fo age in Brazil before and after Human Rotavirus Vaccine Introduction, 1998-2007. Pediatr Infect Dis J 2010;29(7):673-75.

19. PerlS, Goldman M, Berkovitch M, Kozer E. Characteristics of rotavirus gastroenteritis in hospitalized children in Israel. Isr Med Assoc J 2011;13(5):274-7.

20. Rhoingans RD, Constenla D, Antil L, Innis BL, Breuer T. Economic and Health Burden of rotavirus gastroenteritis in the 2003 cohort in eight Latin American and Caribbean countries. Rev Panam Salud Publica 2007;21(4):192-204.

21. Tucker AW, Haddix AC, Bresee JS, Holman RC, et al. Costeffectiveness analysis of a rotavirus immunization program for the United States. JAMA 1998;279(17):1371-6.

22. Rotavirus vaccination coverage among infants aged 5 months-immunization information system sentinel site, United States, June 2006-June 2009. Morb Mortal Wkly Rep 2010; 59(17):521-4. 
ANNEX

\section{Epidemiological and clinical characteristics of acute gastroenteritis according to its etiology (rotavirus or other) in children younger than 5 years old treated in a private institution in the City of Buenos Aires}

\section{TELEPHONE SURVEY}

Once the patient was enrolled in the study, we contacted a family member of the child as of seven days after inclusion. All 275 patients were contacted on the telephone and were asked for the following information:

1. Vaccine received for rotavirus, vaccine brand and date of immunization.

2. Number of doctor visits in a health care facility due to diarrhea.

3. Number of home doctor visits due to diarrhea.

4. Number of telephone calls to the pediatrician due to diarrhea.

5. Number of hospitalization days due to diarrhea.

6. Did the patient receive antibiotics?

7. How many days did the patient receive antibiotics?

8. Did the patient receive rehydration salts?

9. How many days did the patient receive rehydration salts?

10. Did the patient receive intravenous hydration?

11. How many days did the patient receive intravenous hydration?

12. Did the patient receive any other medication?

13. How many days did the patient receive other medication?

14. Did you make any transportation expenses for taking the child to the health care facility?

15. Transportation used (car, taxi, bus).

16. Did you make any transportation expenses to visit the child while hospitalized in the health care facility?

17. Transportation used (car, taxi, bus).

18. Number of visits.

19. Did you loose working hours?

20. Number of lost working hours (total hours between both parents).

21. Did you loose your perfect attendance bonus?

22. Value of perfect attendance bonus.

22. Did you require to hire additional staff to maintain the family routine (babysitter, private taxis)?

23. Cost of hiring additional staff.

24. Did you use additional diapers while diarrhea lasted?

25. Number of additional diapers. 